\title{
NON-INVASIVE FETAL SEX DETERMINATION USING SRY SPECIFIC PRIMERS AND SYBRGREEN REAL TIME PCR
}

\author{
SvecovA I. ${ }^{1}$, Jezkova, E. ${ }^{1,2}$, Hudecova, $\mathbf{I}^{1,2}$, Burjanivova, T. ${ }^{1}$, Biskupska-Bodova, \\ K. ${ }^{1}$ Danko, J. ${ }^{1}$, Lasabová, Z. ${ }^{2}$ \\ ${ }^{1}$ Clinic of Gynecology and Obstetrics and ${ }^{2}$ Department of Molecular Biology, Jessenius Faculty of Medicine, \\ Comenius University and University Hospital, Martin, Slovak Republic
}

\begin{abstract}
Presence of fetal cells and circulating free fetal DNA and RNA in maternal circulation represents the basic concept in developement of non-invasive prenatal diagnostic methods based on molecular biology and genetics. We introduced new methods for free fetal DNA isolation and detection in maternal circulation via DNA isolation from maternal plasma using real-time PCR SYBRGreen targeting and newly designed primers focused in SRY sequence. We determined gender in 46 singleton pregnancies, 22 boys and 24 girls and assessed the analytical and clinical validity. We reached $95.45 \%$ sensitivity and $95.83 \%$ specificity. We suggest improvements in molecular-biological procedures in the discussion, which could be used in studies of clinical utility of non-invasive prenatal diagnosis (NIPD) in decreasing amount of invasive procedures unnecessarily performed.
\end{abstract}

Key words: non-invasive prenatal diagnosis, SRY, real-time PCR, fetal sex determination

\section{INTRODUCTION}

The common methods of prenatal diagnosis can be divided in two large branches, invasive and non-invasive. For the collection of genetic samples, amniocentesis, performed usually in 15th to 18th g.w., and chorion villi sampling, performed from 9th to 12 th g.w. are carried out. Unfortunately, these methods are connected with several serious complications both for mother and the fetus. The miscarriage rate of $1.4 \%$ after amniocentesis and $1.9 \%$ after chorion villi sampling were reported(1). This stressful and traumatic events are the main reason for focusing on the development of non-invasive examination methods in last few years. Both fetal cells and fetal nucleic acids are freely circulating in maternal plasma. Free fetal DNA is very suitable for analysis because of the short life time (16 min);(2). In opposite to fetal circulating cells, it cannot cause false-positive results in subsequent pregnancies. The discovery of circulating cell-free fetal DNA in maternal plasma in 1997 represents the advent of non-invasive prenatal diagnostics (3). There are a number of discrete clinical applications of cff DNA detection and analysis in prenatal screening or diagnosis. These are based upon differences between maternal and fetal genome which can be detected. The main branches using cff DNA are fetal gender assessment, paternally inherited single gene disorders, Rh status and total amount of cff DNA determination. Using the PCR and primers specific for Y chromosome linked genes like SRY or DYS 14, a reliable determination of fetal gender is possible. Early prenatal determination of fetal sex is indicated in fetuses at risk of X-linked disease (e.g.Duchenne muscular dystrophy, adrenoleukodystrophy, Hunter's disease) as

Address for correspondence:

Zora Lasabová RNDr. PhD, Department of Molecular Biology, Jessenius Faculty of Medicine, Comenius University, Kalinciaka 2, 03861 Vrutky, Slovakia. Phone: 00421-43-4286517, e-mail: lasabova@jfmed.uniba.sk 
identification of a male fetus indicates hemizygosity for the $\mathrm{X}$ chromosome and thus potential disease if the mother is a carrier. In the case of male fetus invasive testing is advanced. Gender determination is also indicated in women with positive family history for external fetal genitalia ambiguity and in cases with unclear ultrasound findings or if discrepancy between fetal karyotype and observed external genitalia occurs. It is possible to use this examination in some endocrine disorders including congenital adrenal hyperplasia. Using early gender determination it is possible to avoid the inappropriate dexamethasone treatment in high risk male pregnancies and on the other hand to start the steroid prophylaxis for a short period of time prior to CVS at 11 g.w. (4).

The first report concerning the detection of cff DNA dealt with nested endpoint PCR (3), the subsequent reports developed more sensitive real-time PCR methods based on Taqman technology which are also able to quantify the amounts of amplified PCR products $(5,6)$. A number of scientific reports have been describing different real-time PCR systems to detect fetal gender and in some countries it is offered as a clinical service (7). In this report we describe our own method for the fetal gender determination using the SRY specific primers and SYBRGreen real-time PCR technology on AB 7500 Fast Real Time PCR System.

\section{PATIENTS AND METHODS}

\section{Patients}

Forty-six randomly selected pregnant women from the 20th to 42nd week of gestation were included into study, all familiar with the content and the aim of the study. Informed consent was obtained from all patients. Subsequently 10 milliliter of venous blood was taken into EDTA tube.

\section{Processing of the blood sample}

Blood samples were immediately or maximally 5 hours after collection (stored at $4^{\circ} \mathrm{C}$ ) processed by centrifugation. Firstly, centrifugation at $1600 \mathrm{~g}$ for 10 minutes and $4^{\circ} \mathrm{C}$ was performed. After this step plasma was very carefully taken from the tube without disturbing the maternal buffy coat and placed into $2 \mathrm{ml}$ sterile tube. Maternal buffy coat was also taken and stored at $-20^{\circ} \mathrm{C}$. Subsequently further centrifugation at $16000 \mathrm{~g}$ for 10 minutes and $4^{\circ} \mathrm{C}$ was carried out. Plasma was divided into aliquots $(\sim 200 \mu l)$. Part of the samples was further processed and analyzed immediately and major proportion was sent for a long-term storage at $-80^{\circ} \mathrm{C}$ to blood bank specialized for pathological states in pregnancy.

\section{Isolation of DNA}

Twenty microliter of Proteinase $\mathrm{K}$ was added to $200 \mu \mathrm{l}$ of plasma sample and free fetal DNA was isolated using DNeasy Blood and Tissue Kit (Qiagen, Hilden, Germany) according to manufacturer instructions. DNA was eluted in $30 \mu l$ of the buffer and $2 \mu 1$ of this was used in PCR.

\section{Real-time PCR analysis}

For detection of Y-specific sequences, we designed primers which cover the region of SRY sequence SRY-F-TGGCGATTAAGTCAAATTCGCAT and SRY-R-CCCTAGTACCTGACAATCTAT. Real-time PCR using Power SYBR Green PCR MasterMix (Applied Biosystems, USA) was performed on AB 7500 Fast Real-Time PCR System. Thermal conditions were as follows: initial denaturation 10 minutes at $95^{\circ} \mathrm{C}$, next 49 cycles of two steps; at $95^{\circ} \mathrm{C}$ for $15 \mathrm{sec}$ and at $60^{\circ} \mathrm{C}$ for 1 minute. Each sample was carried out in triplicate and melting curve analysis was performed for validation specificity of the reaction. The assessed SRY status of the fetus was compared to the newborn's gender observed after delivery. 


\section{Statistical evaluation}

For the statistical evaluation Medcalc 10.2 software (Mariakerke, Belgium) was used. A receiver-operator characteristic (ROC) curves were constructed. The sensitivity, specificity, positive predictive value (PPV) and negative predictive value (NPV) in the fetal gender determination were calculated. A p-value $<0.05$ was considered significant.

\section{RESULTS}

\section{Real-time PCR and the gender determination}

We assessed the fetal gender using real-time PCR with SRY targeting primers and SYBRGreen in 46 singleton pregnancies ranging from 20th to 41 st gestational week. Real-time PCR results were compared with gender after delivery and the lowest Ct and the highest positive $\mathrm{Ct}$ were determined at 28.156 and 39.891 for male-bearing pregnancies, respectively (Fig. 1). The resulting criterion for positivity of amplification signal was $\mathrm{Ct}$ $<40$ in two replicates. In 44 cases concordant results were obtained -21 males and 23 females; one falsely predicted male and one falsely predicted female occurred (Fig. 2A).

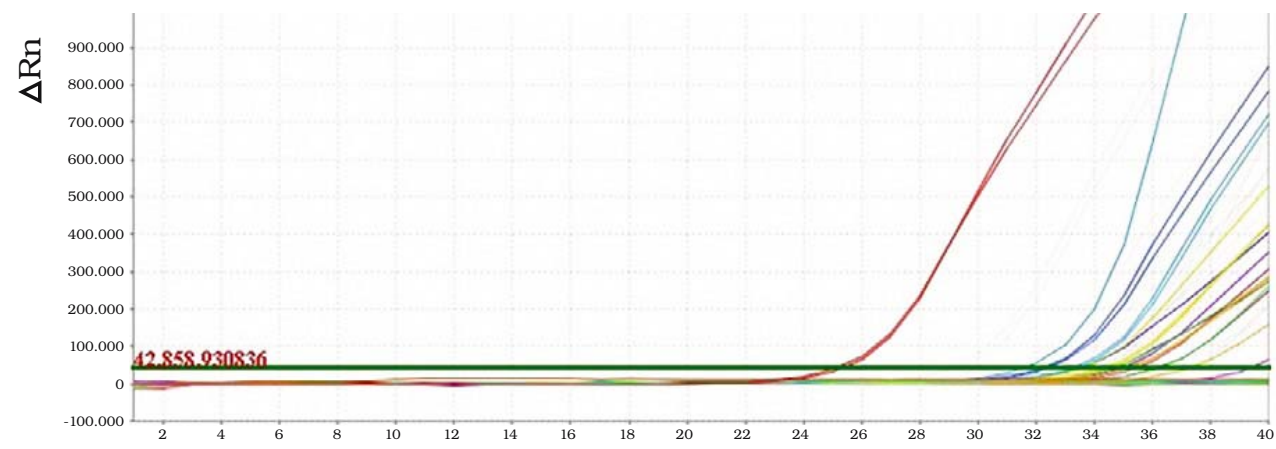

Fig. 1 Amplification plot of real-time PCR with a positive control (red line) and different for $\mathrm{Y}$ sequences positive DNA samples isolated from maternal plasma with $\mathrm{Ct}>30$ and $\mathrm{Ct}$, 40 using SRY specific primers and SYBRGreen. X-axis : number of PCR cycles, Y axis represents fluorescence

A

\begin{tabular}{|l|r|}
\hline $\begin{array}{l}\text { Gender outcome } \\
\text { known }\end{array}$ & 46 \\
\hline $\begin{array}{l}\text { Male - bearing } \\
\text { pregnancies }\end{array}$ & 22 \\
\hline $\begin{array}{l}\text { Female - bearing } \\
\text { pregnancies }\end{array}$ & 24 \\
\hline Falsely predicted male & 1 \\
\hline Falsely predicted female & 1 \\
\hline Accurancy \% (95\% CI) & $44 / 4695,65 \%$ \\
\hline Sensitivity \% (95\% CI) & $\begin{array}{r}21 / 2295,45 \% \\
(77,2-99,9)\end{array}$ \\
\hline Specificity \% (95\% CI) & $\begin{array}{r}23 / 24 \\
\text { S5,83 \% (78,9-99,9) }\end{array}$ \\
\hline $\begin{array}{l}\text { Positive predictive } \\
\text { value (NPV) }\end{array}$ & $95,45 \%$ \\
\hline $\begin{array}{l}\text { Negative predictive } \\
\text { value (NPV) }\end{array}$ & $95,83 \%$ \\
\hline
\end{tabular}

B

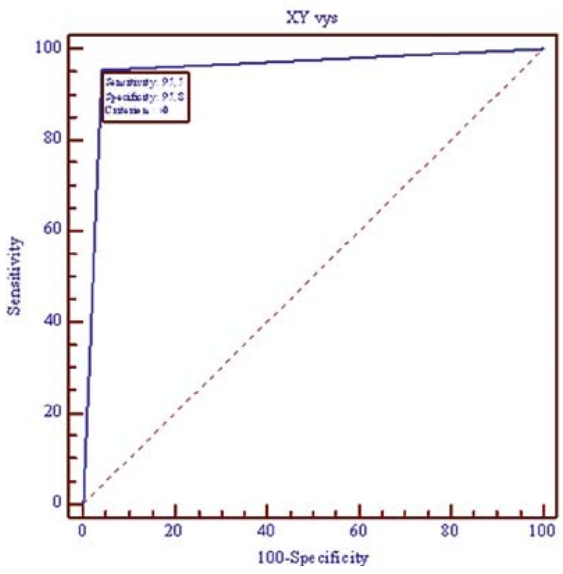

Fig. 2 A The results of the statistical evaluation of the analytical and clinical sensitivity of the test detecting the $\mathrm{Y}$ sequences in the plasma of pregnant women. B Statistical curve is showing the area under curve as 0.956 


\section{Statistical evaluation of the analytical and clinical validity of the test}

The analytical validity is the most basic measure of the test performance and includes sensitivity and specificity associated with the assessed condition. In our case, the assessed condition was the presence of the $\mathrm{Y}$ sequences in the clinical sample. The clinical validity of a test measures how well it predicts a clinical condition, in our case the male gender of a child. In this situation the analytical and clinical validity are of the same values.

The analytical and clinical sensitivity of the method was evaluated as the detection of Y sequences in above mentioned samples and compared to the male bearing pregnancies and was assessed as $95.45 \%$. The analytical and clinical specificity was evaluated as proportion of negative test results $(\mathrm{Ct}>40)$ compared with female-bearing pregnancies and was assessed at 95.83\%. The accuracy of this method was $95.65 \%$ calculated as proportion of concordant results to all samples tested (Fig. 2A). The area under the curve (AU) was 0.956; the significance level was $\mathrm{p}=0.0001$ (Fig. 2B). The positive predictive value (PPV) was $95.45 \%$ which means that in $95.45 \%$ cases we should be able to identify a male fetus. The negative predictive value (NPV) is $95.8334 \%$. By other words, we are able to identify in $95.8334 \%$ a female fetus (Fig. 2A).

\section{DISCUSSION}

This study aims to determine fetal sex using cffDNA from maternal plasma by realtime PCR method with SYBR Green chemistry together with newly designed primers.

According to our results we confirmed a high accuracy of the described method, but presence of false negative and false positive results has been observed. Some facts can explain reasons for this situation. Firstly, in the case of false positivity, the contamination with male DNA is the main factor for distortion of results. Therefore, much attention has to be paid to the step of sample processing. It is inevitable to perform blood sampling exclusively by female staff. Real-time PCR analysis detecting Y-specific sequences is extremely prone to contamination, therefore the above mentioned precautions have to be taken into account to precede such errors. Another issue concerns the type of chemistry used to detect PCR product by real-time PCR. Generally, SYBR Green chemistry uses fluorescent dye which binds to any double-stranded DNA, including nonspecific double-stranded DNA sequences, thus generating potential false positive results. For higher specificity of the test, more suitable option using TaqMan probes is recommended, where specificity and sensitivity can reach almost 100\% (8).

On the other hand, detection of false negative results is another problem which has to be resolved. The occurrence of this phenomenon might be caused by insufficient amount of DNA added to PCR reaction or by problems made in the step of DNA isolation. To confirm the presence of cell free fetal DNA in the sample, a universal fetal marker has to be included to the test to assure any false negative results has been detected. More approaches have been described for reliable and effective confirmation of fetal genetic traces in maternal plasma in female fetuses. A good possibility to confirm cffDNA in sample is testing bi-allelic insertion/deletion polymorphisms (9). DNA from maternal plasma is tested for polymorphisms that are absent from the maternal genome and if positive signal is obtained, this indicates presence of cffDNA in maternal plasma. The study of Hill et al. used analysis of sex independent markers or polymorphisms in a few female cases but was not pursued as the process was very labour intensive and the markers were not informative in $>60 \%$ of cases (10). However, more promising candidates for this purpose seem to be epigenetic markers with different methylation pattern between mother and fetus. Promotor region of tumor-suppressor gene RASSF1A was tested (11) and was considered as a preferable choice in comparison with Maspin gene which has opposite methylation pattern (12). 
Non invasive prenatal determination of fetal gender via cffDNA is an important step in the correct management of several very serious disorders. Mother carriers with a severe risk of X-linked genetic disorders in their fetuses and positive family history are able to avoid unwanted invasive diagnostics in female fetuses. Couples with a high risk for congenital adrenal hyperplasia are able to prevent unnecessary dexamethasone administration in their child. Confirmation of gender in cases of genital ambiguity, in discrepancies between genetic sex as determined following invasive testing /amniocentesis or chorion villi sampling/ can be very useful in prenatal care management. For the future, we are going to develop a method for the gender determination based on Taqman technology and we plan to include the universal fetal DNA marker in our investigations.

\section{REFERENCES}

1. Tabor, A., Vestergaard CH., Lidegaard O. Fetal loss rate after chorionic villus sampling and amniocentesis: an 11 year national registry study. Ultrasound obstet gynecol 2009, 34: 12-13.

2. Lo YMD., Zhang J., Leung TN., Lau TK., Chang AMZ., Hjelm NM. Rapid clearance of fetal DNA from maternal plasma. Am J Hum Genet 1999, 64: 218 - 224.

3. Lo Y.M., Corbetta N., Chamberlain P.F. et al.: Presence of fetal DNA in maternal plasma and serum. Lancet 1997; 350: 485-487.

4. Avent ND., Chitty LS. Non - invasive diagnosis of fetal sex, utilisation of free fetal DNA in maternal plasma and ultrasound . Prenat Diagn 2006, 26: 598-603.

5. Lo Y.M., Tein M.S., Lau T.K., et al. Quantitative analysis of fetal DNA in maternal plasma and serum: implications for noninvasive prenatal diagnosis. Am. J. Hum. Genet. 1998; 62: 768-775.

6. Finnig K.M., Chitty L.S.: Non-invasive fetal sex determination: Impact on clinical practice. Seminars Fetal Noenatal Med 2008; 13: 69-75.

7. Lau T.W., Leung T.N., Chan L.Y., et al. Fetal clearance from maternal plasma is impaired in preeclampsia. Clin. Chem. 2002; 48: 2141-2146.

8. Hromadnikova I., Holubova B., Hridelova D. et al.. Replicate real - time PCR testing of DNA in maternal plasma increases the sensitivity of non - invasive fetal sex determination. Prenat diagn 2003, 23: 235 238

9. Page-Christiaens GC, Bossers B, van der Schoot CE, de Haas M. Use of bi-allelic insertion/deletion polymorphisms as a positive control for fetal genotyping in maternal blood: first clinical experience. Ann N Y Acad Sci 2006. 1075: 123-129.

10. Hill M, Finning K, Mrtin P, Hogg J, Meaney C, Norbury G, Daniels G, Chitty LS. Non-invasive prenatal determination of fetal sex: translating research into clinical practice. Clin Genet 2010: 1-8.

11. Chan K.C., Ding C., Gerovasilli A,Yeung S.W., Chiu R., W.K., Leung T.N., Lau T.K., Chim S.S., Chung G.T., Nicolaides K.H., Lo Y.M.D.. 2006. Hypermethylated RASSF1A in maternal plasma: a universal fetal DNA marker that improves the reliability of noninvasive prenatal diagnosis. Clin Chem. 52: 2211-2218

12. Chim S.S., Tong Y.K., Chiu R.W., Lau T.K., Leung T.N., Chan L.Y., Oudejans C.B., Ding C., Lo Y.M.D. 2005 Detection of the placental epigenetic signature of the maspin gene in maternal plasma. Proc. Natl. Acad. Sci.USA. 102(41): 14753-14758

Acknowledgement: This work was supported by project "Center of Excellence of Perinatology Research (CEPV II)”, ITMS code: 26220120036, which is co-financed by EU sources and by MZ SR 2007/60-MFN-03 Ministry of Health grant .

Received: April 14, 2011

Accepted: April, 28, 2011 